\title{
MEDICINA LEGAL
}

\section{Resposta a uma consulta}

Os paes da Snra. A. deram queixa contra H. por crime de defloramento.

A authoridade policial a quem foi presente a queixa nomeou peritos os Drs. B. e C., formulando os seguintes quesitos.

\section{I}

Se houve defloramento;

II

Qual o meio empregado;

III

Se houve copula carnal; 
Se houve violencia para fim libidinoso;

$$
\mathrm{V}
$$

Qual seja;

\section{VI}

Se em virtude do meio empregado ficou a offendida impossibilitada de resistir e defender-se.

Os peritos, depois de examinarem a offendida, declararam que o utero se acha desenvolvido por um producto da concepção de cinco para seis mezes, tendo por esse motivo deixado de proceder de visu ou pelo exame directo á averiguação do estado das partes sexuaes. E por isto respondem aos quesitos formulados pela maneira seguinte:

I

Sim. Houve defloramento;

II

O membro viril;

III

Sim. Houve copula carnal;

IV

Não podem responder, visto o tempo; 


\section{V}

Prejudicado;

\section{VI}

Sim.

\section{Pergunta-se:}

Não tendo os peritos examinado de visu o estado das partes sexuaes, como se verifica do relatorio que apresentaram, podiam concluir que houve defloramento?

\section{II}

Sem terem procedido ao exame de differentes regiơes do corpo para verificarem a existencia actual ou vestigios de lesões, podiam os peritos affirmar que não houve violencia para fim libidinoso? $\left(4 .^{\circ}\right.$ e $5 .^{\circ}$ quesitos).

\section{III}

Sempre que se realiza o defloramento e a este segue-se a copula carnal, fica snb-entendido ipso-facto que a offendida estava impossibilitada de defender-se e resistir? (6. quesito).

IV

O presente auto de corpo de delicto está de accordo com os preceitos da Medicina Legal e do Direito? 


\section{$-158-$}

$\S$

Eis a consulta que me foi feita por distincto advogado em Santa Cruz das Palmeiras, consulta esta que importa complexidade de questões, cada qual mais importante. E, como respondi syntheticamente, prestando-se aliás o assumpto á desenvolvimento util e amplo, entendi fasel-o agora em traços mais largos, emittindo meu modo de vêr sobre um dos pontos escabrosos da medicina legal, quer se o encare pelo lado da medicina, quer, e principalmente, pelo do direito, sob cujo aspecto, parece-me, dever elle ser mais considerado. E, para melhor orientação e methodo, em resposta ás perguntas feitas pelo illustre advogado, começo pela primeira.

Não tendo os peritos examinado de visu o estado das partes sexuaes, como se verifica do relatorio que apresentaram, podiam concluir que houve defloramento?

Desde que do exame verificaram os peritos estar a paciente gravida de 5 para 6 mezes, podiam, como fizerain, prescindir do exame das partes sexuaes e concluir pela defloração. Perda dos signaes caracteristicos da virgindade por effeito da união sexıal do homem e da mulher, a defloração, medicamente falando, só póde ser affirmada na - ausencia daquelles signaes caracteristicos. E' opinião acceita por todos os autores, que o mais importante, sem ser o unico, entre esses signaes de virgindade, é a membrana hymen cuja ruptura e laceração consecutivas á intromissão do membro viril na vagina, constitue o criterio mais seguro para o diagnostico da defloração. Mas, tambem é verdade que dadas certas condições de 
conformação, natureza e estructura hystologica, a hymen póde dar passagem ao penis, conservando-se integra. $\mathrm{E}$ tanto isto contribue para difficultar aquelle diagnostico,"que Vibert, mesmo, aconselha nestes casos que os peritos respondam não estar a paciente deflorada no sentido medico ia palayra: mas, ser tal a conformaça de suas partes genitaes, que ella póde ter relações sexuaes, sem que se désse a dilaceração da membrana hymen. Devido ainda a essas condições é que se explica a existencia dessa membrana em prostitutas, como affirmam, além de outros, Parent-- Duchatelèt.

Eu mesmo posso affirmar, na minha qualidade de medico legista, que no Rio de Janeiro tive occasião de ver membranas dessa natureza em grande numero, o que levou-me como leva-me a declarar ser isto frequente. Occorre-me a proposito um caso tão cercado de difficuldades, que só no fim de terceiro exame pude affirmar estar a rapariga deflorada.

Era ella cle cerca de i 6 annos, bem constituida e possuidora de fórmas dignas de serem modeladas. A vulva tão bem conformada que trahia a de uma virgem; a membrana hymen lá se achava integra em sua fórma labiada e tão perfeita, que inclinei-me á crença de que tudo quanto referia era verdade: ella negava estar deflorada. Só no fim do terceiro exame como disse, foi que a luz fez-se, affirmando eu a defluração. Mas como? Por meio de um signal para mim de tão grande valor e tão frequentemente observado, que não sei qual dos dois mais pesará -.. a membrana hymen ou a fossa navicular-. Foi este o signal que me salvou. A fossa navicular, protrahida a copula, acompanha o eixo da vagina a custa do membro viril, vae pouco a pouco se adelgaçando até seu completo desfasimento. Levado pelas modificações da fossa navicular, distendi os graniles labios e a 
hymen acompanhando este distendimento mostrou-me seu orificio, por atravez do qual introduzi o dedo minimo, depois o annular, o médio, o indicador, não introduzindo o pollegar por não ser necessario. Então, vi as pregas da vagina, das quaes algumas já quasi desfeitas; bem como notei que esse canal estava dilatado e era tão dilatavel, que a elle bem se podia applicar a espirituosa phrase de Legrand du SaulesSer uma vagina complacente - Confessou a paciente tudo. Que de longo tempo tinha relações com um estalajadeiro em cuja casa morava.

Como vê-se é este um caso, além de outros, narrados pelos autores e observados por mim, que vem confirmar ser a membrana hymen o mais importante entre os signaes physicos da virgindade, mas não o unico. Assim sendo, todas as vezes que a duvida assalte o espirito dos peritos, não devem elles deixar de convergir sua attenção para a fossa navicular afim de melhor poderem observar o conselho pratico dado por Vibert, como já fiz ver. Tudo isto refere-se a virgindade physica a que se julgam os peritos subordinados.

Mas justamente por isto e por muito -mais que poderia dizer, inclino me para a opinião dos que, como Buffon, attendendo muitas vezes a difficuldade da prova material, entendem ser a defloração um .facto mais de indole moral; dando-se o caso da mulher poder ser casta sem ser virgem e virgem sem ser casta.

Entendo, pois, que não se deve separar um elemento do outro e sendo assim, parece-me que a feição juridica da especie deve ser a que hade preponderar.

$\mathrm{Na}$ consulta feita os peritos encontraram a paciente gravida de 5 para 6 mezes e por isso deixa- 
ram de examinar as partes sexuaes externas; demos de barato que o fizessem e encontrassem a hymen perfeita. De duas uma; ou esta membrana de natureza extensivel deu passagem ao membro viril, sem romper-se, e a copula foi fecundante; ou o membro por qualquer circumstancia, não podendo atravessar a hymen e penetrar na vagina, a ejaculação deu-se extra vas, como diziam os antigos, e parte do liquido seminal passando pelo orificio da membrana foi tambem fecundar a mulher.

Em ambos os casos deu-se a defloração, a mulher foi deflorada, não no sentido medico da palavra, mas no sentido juridico. $E$, para os mais exigentes, se a ruptura da hymen é o criterio que deve guiar os peritos, esta ruptura não dando-se, como podia não ter-se dado no caso em questão, hade forçosamente dar-se, por occasião-do parto, pois a paciente acha-se gravida de 5 para 6 rnezes, e assim satisfeita aquella exigencia.

Julgo, pois, que os peritos respondendo como fizeram, direndo a paciente estar deflorada, sem terem examinado suas partes sexuaes externas, visto encontrarem-n'a gravida, procederam correcta e scientificamente.

O sabio Rei da Judéa, Salomão, considerando já no seu tempo a gravidade do assumpto, disse desconhecer quatro cousas; o vastro da cobra sobre as pedras, do vento no ceu, do navio no mar e. viam viri in adolescentia. Effectivamente; se é facil as vezes concluir-se pela defloração, outras, as difficuldades se accumulam á ponto de reclamarem muita cautela e reserva da parte de quem, com sua opinião, põe em jogo a liberdade, a honra e até a vida de seu semelhante. 
Assim, bem opinaram os peritos pela defloração da paciente, respondendo ao quisito que lhes foi formulado, de accordo com a regra antiga do formulario do processo; extranhando, porém que $\mathrm{o}$ fizessem quanto aos segundo e terceiro quisitos da mesma regra, como fizeram. Affirmando a defloração, de accordo com a doutrina que propugno, a resposta aos segundo e terceiro quisitos são ociosas. Ociosas, porque vindo a defloração seguida da fecundação, foi o membro viril o meio (?) empregado e portanto houve contacto carnal com ejaculação. A primeira resposta comprehende, pois, as outras duas.

Sem terem procedido ao exame de differentes regiões do corpo para verificar a existencia actual ou vestigio de lesões, podiam os peritos affirmar que não houve violencia para fim libidinoso? ( $4 .^{\circ}$ e $5 .^{\circ}$ quesitos ).

A resposta dada pelos peritos,--que não podiam responder visto o tempo em que foi praticado o clelicto-obriga-me a algumas considerações.

A violencia para fim libidinoso tanto é physica como moral.

Pelo modo porque o digno advogado formulou a consulta, deprehende-se que censurando us peritos por não terem examinado as differentes regiões do corpo, só e só o preoccupava a violencia physica, isto é: a caracterisada por algumas lesões corporaes.

Emprega-se a violencia physica para obter-se uma cousa contra a vontade de seu dono. 
No caso que discuto, a paciente ou entregou-se gostosamente nos braços do amante ou, então, foi forçada, violentada.

$\mathrm{Na}$ primeira hypothese trata-se simplesmente de defloração; na segunda, do estupro aggravado da defloração.

O estupro, neste caso, deve consistir na violencia physica que motivou a censura aos peritos.

Conhecidas são as regiões ou partes do corpo, em que se encontram as violencias para fim libidinoso: a face, bocca, pescoço, braços, mamas, ventre, partes pudendas e coixas. A uma mulher que lucta em defesa de sua honra, o aggressor animado por erotica brutalidade, procura, evitando-lhe os gritos, subjugal-a Ecchymoses, erosões, excoriações são as lesões que no commum dos casos, se encontram n'essas partes acima indicadas.

Ora, procedendo-se ao exame 5 ou 6 mezes depois do facto consumado, os peritos bem andaram em dìer que não podiam responder, visto tempo decorrido, pois semelhantes lesões necessariamente já estariam desapparecidas, ou caso fossem ellas mais importantes, os vestigios encontrados podiam não terem resultado de violencias para aquelle fim.

$\mathrm{E}$, de facto. Só quem não sabe a natureza d'estes exames, é que desconhece o ardil, astucia, a ousadia da parte da queixosa ou de sua propria mãe, no intuito unico de extorquir dinheiro, do chantage.

Como querer-se, pois, obrigar os peritos a responderem determinada e expecificadamente?

Examinavam elles o corpo da paciente; encontravam, mesmo, algumas cicatrizes superficiaes e antigas: como dizerem terem ellas provindo de violencia para aquelle fim? 
Lesões d'esta natureza só podem e devem assim ser consideradas, quando acompanham os signaes recentes de defloração. Fazel-o de modo contrario é um attentado a reputação dos peritos e aos interesses sagrados da justiça.

Assim penso e se tal não fosse, muitas veżes me teria compromettido dando como violencias para fim libidinoso lesões proposital ou accidentalmente feitas, como o inquerito depois provou.

Nem posso comprehender por outro modo e muito menos censurar-se os peritos, que com sua resposta mantiveram-se na altura da sciencia e da verdade.

E' costume que vem de longe querer-se obter em materia de corpo de delicto respostas affirmativas ou negativas, dadas de modo vago e dogmatico.

Sobre não ser possivel, constitue isto practica perigosa não só para quem, n'estes termos, dá como para quem recebe a resposta. Em medicina legal deve-se sempre attender para tudo quanto fôr intrinseco e extrinseco ao individuo, en beneficio da tranquilidade de todos.

Sempre que se realisa o defloramento e a este segue-se a copula carnal, fica subentendido ipso-facto que a offendida estava impossibilitada de resistir e defender-se? Esta pergunta feita pelo digno advogado refere-se ao $6 .^{\circ}$ quesito feito pelia authoridacle, nos seguintes termos: "Se em virtude do meio empregado ficou a offendida impossibilitada de resistir e defender-sẹ e ao qual os peritos responderam «Sim». 
Lamento e o faço com dôr, ver-me obrigado a declarar que os peritos d'esta vez claudicargm ou cochslaram.

Em primeiro logar não posso deixar de acceitar, na falta de outra explicação, que esse meio empregado fosse outro que a violencia physica, da qual já me occupei. E nem pode-se admittir outra interpretação, pois que nem a authoridade como o advogado se quer de leve fazem menção de outro qualquer meio com o auxilio do qual o agente lançasse mão contra a paciente.

Por isto, tudo quanto passo a considerar refere-se ao meio como violencia physica impossibilitando a offendida de resistir ou defender-se.

E' principio corrente na sciencia que, salvo casos muito excepcionaes, um só homem possa deflorar uma mulher, contra à vontade d'esta: ainda mesmo derrubada e subjugada, ella pode evitar que o acto se consumma: Basta um simples movimento dos flancos.

Certa imperatriz famosa a quem uma dama da côrte queixou-se ter sido violentada por um militar, fel-o vir a sua presença, tomou-lhe a espada que entregou aquella dama e empunhando a bainha ordenouthe que a introduzisse em seu logar. Por mais que esta $n$ fizesse, não conseguiu; pois aquella, desviando a bainha para um e outro lado, a espada não poude penetrar. Este facto vem comprovar aquella minha asserção: em materia de estupro essa resistencia empregada pela paciente, disperta muita meditação, por quanto deve ella anteceder e acompanhar a violencia até o fim.

A não ser que as forças se esgotem ou que uma syncope surprehenda na lucta a paciente, esta querendo pode evitar, como já disse, sua defloração. 
Mas qual o criterio para julgar-se que o facto consummou-se apezar da resistencia empregada?

E' sabido muitas vezes que essa resistencia accentuada no começo, transforma-se em accordo no meio e torna-se em desejo no fim. Sendo pois indispensavel aquella condicção acima dita, comprehende-se o quanto é difficil poder-se avaliar o gráo de resistencia empregada e allegada pela paciente em seu favor. O facto da defloração vir seguida da copula carnal, conforme pergunta o advogado, não subentende que a offendida estava impossibilitada de resistir e defender-se, a menos das duas hypotheses acima figuradas.

Em que dado, pois, basearam-se os peritos para responderem affirmativamente ao $6 .^{\circ}$ quesito formulado pela authoridade? Set, ao menos, elles tivessem examinado o curpo da paciente e encontrado vestigios de lesões, conforme o menor ou maior gráo de sua importancia, poderiam quando muito e só provavelmente assim concluirem. Não tendo feito, como disseram, sua resposta retrograda a sciencia á seculos remotissimos, em que se desconheciam o seus mais comesinhos rudimentos.

Não sei qual a edade das duas partes, pois não consta da consulta, nem tão pouco qual a constituição organica de ambas. Tal omissão, no entretanto, obriga-me a outras consideraçoes que talvez possam aproveitar a casos semelhantes.

Disse, e em geral assim é, que um só homem não póde deflorar uma mulher, caso esta não queira. Além dos casos acima figurados, accresce mais o da proporção ou desproporçắo da edade: um homem moço, bem constituido, não deflora, contra a vontade, uma mulher nas mesmas condições. Quando esta apezar de moça acha-se esgotada por qualquer soffri- 
mento que tem-lhe diminuido as forças de reacção, ou quando trata-se de uma infeliz, cujos clarões do entendimento se extinguiram, então o acto pode consummar-se, pois, a vontade, essa faculdade que tem o homem de poder agir livremente, desappareceu.

No caso em questão, não trata-se d'isto. Está em jogo uma mulher que foi deflorada, que concebeu em seguida e a qual, pelo facto da copula carnal, os peritos consideraram-n'a incapaz de resistir e defender-se.

Não sei mesmo onde foram elles beber semelhante inspiração e qual o criterio para tão arrojada affirmativa.

O facto da copula não impossibilitava a resistencia e a defesa. Estas, postas em acção desde o começo seriam uma garantia para a paciente. Desde que porém houve a deflọração seguida da concepção, seria melhor e mais sensato que os peritos tivessem em mente e praticassem o sabio conselho de Brouardel - antes dizer não sei, que mais tarde, eu não sabia.Eis minha opinião a respeito da consulta que me fizeram, apoiando-a não só nos preceitos conhecidos da sciencia, como em grande numero de factos de observação propria. A muito mais se presta o assumpto, merecedor de maior desenvolvimento: mas na contingencia de uma resposta, entendi não fazel-o, enviando o leitor para os autores, alguns dos quaes proficientemente discutem a questão.

S. Paulo, 20 de Junho de i 896.

Dr. Emancio de Carvalho 